ing. An entirely different situation arises in the preparation of high protein animal feed, however, as then the whole fish is used. Second, the analysis of body fat of barracuda and similar nonmigratory "fat accumulators" is a useful method of estimating local pollution, provided that year-round analyses are carried out because spot checking would lead to erroneous results.

\section{INSECT VISION}

\section{Superposition}

from our Insect Physiology Correspondent IT is now more than eighty years since Exner published his classic monograph on the optics of the compound eyes of insects and crustaceans. Exner's views have long been accepted virtually unchallenged; only in the past few years have his results been subjected to renewed critical tests, notably by G. A. Horridge and his colleagues. The classic theory of mosaic vision by the compound eye is commonly attributed to Johannes Müller, early in the nineteenth century; but it had, in fact, been put forward by Robert Hooke a century and a half earlier. According to this theory the retinal image is formed by the apposition of partial images produced by each facet of the compound eye. These partial images convey to each retinal element, or rhabdom, a stimulus characterized by their average intensity of illumination, and the resulting definition in the "apposition image" depends on the number of facets in the surface of the eye.

The most original contribution by Exner was the theory that in the eyes of nocturnal insects and some Crustacea, in the dark adapted state, the screening pigment around the optical pathway from the crystalline cone to the receptor rhabdom is withdrawn between the crystalline cones, leaving a clear zone below; and that the refractive properties of the lens cylinder, or crystalline cone, are such that light rays are deflected back towards the side from which they enter the facet, in such a way that they converge in the clear zone, and a single retinal element receives light not only from its own facet, but also light from the same point source entering through a group of neighbouring facets. The resulting image was named by Exner a superposition image. It was demonstrated most convincingly in isolated portions of the eye of the glow-worm Lampyris. Exner noted that the erect image so formed did not fall precisely at the level of the retina-but he suggested that this might be due to his using isolated and cleaned preparations from the eye.

Horridge first examined the eye of the firefly Photuris and found that no superposition image could be demonstrated. He termed the eyes with a wide gap between the crystalline cones and the receptor rhabdoms of the retina clear zone eyes (as opposed to superposition eyes, which implies a particular mode of operation.) In the mealmoth Ephestia there are glassy threads extending from the lens of each ommatidium to the rhabdom. These threads act as light guides which conduct most of the light received by each facet to its own rhabdom and thus a normal apposition image is produced. Furthermore, there is some scattering of light at the inner extremity of the lens and some of this reaches the retina by an indirect route. There is also a certain amount of refraction of the type described by Exner in the superposition eye-but it is too indefinite to form a useful superposition image. The eye in the dark adapted state enjoys greater general illumination but any contribution to image production must be highly diffuse.

In their most recent report, however, Horridge, Giddings and Strange (Proc. Roy. Soc. Lond., B182, 457 ; 1972) show that in the skipper butterflies (Hesperidae), which are day-flying insects, there is a wide clear zone which is never interrupted by screening pigments; the pigment remains permanently between the crystalline cones even in the brightest illumination. There are glassy threads from the cones to the rhabdoms, but these are so fine that they cannot serve as wave guides for light. In the eye of these skipper butterflies the superposition principle is fully operative under all conditions of lighting and gives rise to an erect image that is tolerably sharp and is formed at the level of the receptors. Ingenious new methods were devised by which the image can actually be seen inside the eye. It would seem that although the

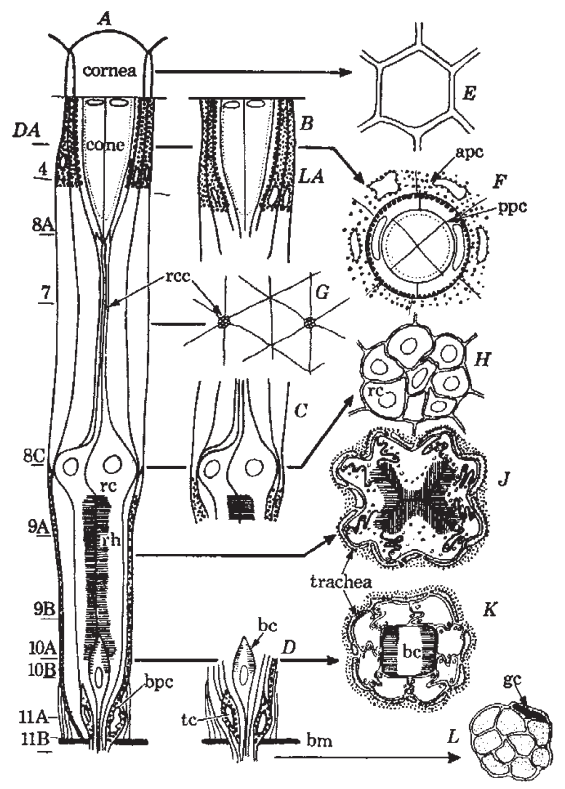

Diagram of an ommatidium, as found by electron microscopy in the skipper butterflies (figure from Horridge et al. Proc. Roy. Soc., B182, 460; 1972). $a p c$, Accessory pigment cell ; $b c$, basal retinula cell ; $b m$, basement membrane; $b p c$, basal pigment cell ; $g c$, glial cell ; ppc, principal pigment cell ; $r c$, retinula cell body; $r c c$, retinula cell column ; $r h$, rhabdom ; $t c$, tracheal cell.

superposition principle does not operate in all clear zone eyes, in some insects it really does exist in a highly efficient state.

\title{
TYMV RNA as an Amino-acid Donor
}

THE single stranded genomic RNA of turnip yellow mosaic virus (TYMV) has some striking similarities to transfer RNAs. The structure of the $3^{\prime}$ end of this viral RNA apparently resembles the structure of a tRNA and the last three bases of the viral RNA are CpCpA. The ultimate $A$ residue is metabolically labile and can be added by tRNA nucleotidyltransferase and the viral RNA can be charged with valine by valyl-tRNA synthetase. These findings prompted Haenni et al. to determine whether or not charged TYMV RNA can donate its valine residue to nascent polypeptide, and as they report in Nature New Biology next Wednesday (February 7) the viral RNA can mimic tRNA in protein synthesis.

In a protein synthesizing cell free system programmed with poly $(\mathrm{G}, \mathrm{U}, \mathrm{C})$ valyl TYMV RNA donates its valine to polypeptide at about one-fiftieth the efficiency of valyl-tRNA. Further- more, this reaction is blocked by puromycin and experiments with inhibitors of aminoacyl-tRNA synthetases prove that valyl TYMV RNA donates its valine directly.

In a companion report Prochiantz and Haenni describe a series of experiments which indicate that TYMV RNA is a substrate for the Escherichia coli endonuclease which converts tyrosine precursor tRNA to mature tRNA. This finding suggests that when valyl TYMV RNA donates its valine residue during protein synthesis the $3^{\prime}$ terminal portion of the TYMV RNA, which resembles tRNA, is cleaved from the rest of the viral RNA molecule.

From these results it seems plausible to speculate that the evolution of the TYMV genome has involved either the convergent evolution of a tRNA-like sequence or the attachment of a tRNA to the rest of the viral RNA molecule, an intriguing situation. 